\title{
Respiration and sleep in Parkinson's disease
}

\author{
MCP APPS, PC SHEAFF, DA INGRAM, C KENNARD, DW EMPEY \\ From the Department of Respiratory Medicine and the Section of Neurological Sciences, The London \\ Hospital, London, UK
}

SUMMARY Sleep and respiration during sleep were studied in patients with idiopathic Parkinson's disease, patients with Parkinsonism with autonomic disturbance, and normal age and sex matched controls. Patients with idiopathic Parkinson's disease showed significantly reduced REM sleep, and more frequent and prolonged waking throughout the night. Hypoventilation and sleep apnoea did not occur in the idiopathic Parkinson's disease or normal groups, but respiration was disorganised with frequent central and obstructive apnoeas in the autonomic disturbance group. Respiratory rate during non rapid eye movement sleep was similar in the idiopathic Parkinson's disease and normal groups, but patients with idiopathic Parkinson's disease showed tachypnoea awake and during REM sleep.

Abnormal sleep has been described in patients with Parkinson's disease. They sleep poorly, frequently waking, and have little stage III/IV or REM sleep. ${ }^{1-3}$ It has been proposed that these abnormalities are related to a reduction in brain amines, ${ }^{4}$ and treatment of Parkinson's disease with levodopa or bromocryptine may lead to an improvement in sleep quality. ${ }^{56}$ None of these studies has made any comment on respiration during sleep. McNicholas et $a l^{7}$ studied three patients with idiopathic Parkinson's disease, but reported the data on sleep for their normal subjects and Parkinsonian patients together, only providing respiratory data during sleep separately. Irregular respiration was noted to be a feature of patients with Parkinsonism following encephalitis lethargica, and was said to be worse during sleep. ${ }^{8}$ More recently there have been several case reports of hypoventilation in patients with post-encephalitic Parkinsonism, ${ }^{9-11}$ or associated with familial Parkinson's syndrome, ${ }^{12}{ }^{13}$ but none of these reports described sleep patterns.

We have studied the patterns of sleep and respiration in patients with idiopathic Parkinson's disease, to document any evidence of hypoventilation or respiratory arrhythmias associated with this condition. This group has been compared with normal controls, and Parkinsonian patients with autonomic disturbance, one of whom had Shy Drager syndrome.

Address for reprint requests: Dr MCP Apps, The London Hospital, Whitechapel, London E1 1BB, UK.

Received 28 September 1984 and in revised form 22 March 1985. Accepted 5 April 1985

\section{Methods}

We studied 12 patients ( 3 female, 9 male, mean age 57.9 years SD \pm 8.99 years) with idiopathic Parkinson's disease, and compared them with 12 normal control subjects, matched for age and sex (mean age 56.8 years $\mathrm{SD} \pm 8.2$ years). In addition two patients with Parkinsonian features and autonomic dysfunction were studied. All of the patients were in a stable clinical state, and were on optimal therapy with anti-Parkinsonian drugs. None of the patients or controls had any history of respiratory or cardiac disease.

The subjects slept on a hospital bed in a quiet darkened room, with the investigator and recording equipment in an adjoining room. The Parkinsonian patients were studied for two nights, and the normal controls, who were all members of staff and accustomed to investigation, for one night. In the Parkinsonian patients the record from the second night of study was taken for analysis. Sleep was assessed by standard methods. ${ }^{14}$ The electroencephalogram (EEG) was recorded from position $\mathrm{C} 4 \mathrm{~A} 1$, and the electro-oculogram was recorded from two electrodes placed obliquely, one above the outer aspect of the left eye, the other placed below the outer aspect of the right eye. The submental electro-myogram (EMG) was recorded from electrodes positioned on the right side of the neck. The electrocardiogram (ECG) was recorded from electrodes on the shoulders in lead I configuration. All of these recordings were obtained using $10 \mathrm{~mm}$ silver cup electrodes. Airfiow was assessed at the nose and mouth by thermistors mounted on nasal cannulae, or with a laryngeal microphone. Respiratory movements were recorded with inductance coils (Respitrace) placed around both chest and upper abdomen. Haemoglobin oxygen saturation was measured with a Hewlett Packard ear lobe oximeter attached to the ear throughout the night. All information was recorded onto paper on a 16 channel 
Table Patients details

\begin{tabular}{|c|c|c|c|c|c|}
\hline Age (yrs) & Sex & $\begin{array}{l}\text { Years with } \\
\text { Parkinson's disease }\end{array}$ & $\begin{array}{l}\text { Severity } \\
(\text { Hoehn \& Yahr })^{39}\end{array}$ & Drug therapy & \\
\hline 55 & $\mathbf{M}$ & 7 & III & Orphenadrine $50 \mathrm{mg}$ & t.d.s. \\
\hline $\begin{array}{l}64 \\
48 \\
54\end{array}$ & $\begin{array}{l}\mathbf{M} \\
\mathbf{M} \\
\mathbf{M}\end{array}$ & $\begin{array}{r}4 \\
2 \\
12\end{array}$ & $\begin{array}{l}\text { II } \\
\text { III } \\
\text { II }\end{array}$ & $\begin{array}{l}\text { Sinemet } 275 \\
\text { Sinemet } 275 \\
\text { Bromocryptine } 5 \mathrm{mg} \\
\text { Madopar } 125 \mathrm{mg}\end{array}$ & $\begin{array}{l}\text { t.d.s } \\
\text { t.d.s. } \\
6 \text { times a day } \\
6 \text { times a day }\end{array}$ \\
\hline $\begin{array}{l}68 \\
70\end{array}$ & $\begin{array}{l}\mathbf{M} \\
\mathbf{M}\end{array}$ & $\begin{array}{r}3 \\
12\end{array}$ & $\begin{array}{l}\text { II } \\
\text { III }\end{array}$ & $\begin{array}{l}\text { Sinemet } 275 \\
\text { Bromocryptine } 10 \mathrm{mg} \\
\text { Levodopa } 1 \mathrm{gm}\end{array}$ & $\begin{array}{l}\text { t.d.s. } \\
\text { t.d.s. } \\
\text { t.d.s. }\end{array}$ \\
\hline $\begin{array}{l}60 \\
57\end{array}$ & $\begin{array}{l}\mathbf{M} \\
\mathbf{M}\end{array}$ & $\begin{array}{r}3 \\
10\end{array}$ & III & $\begin{array}{l}\text { Sinemet } 110 \\
\text { Bromocryptine } 5 \mathrm{mg} \\
\text { Sinemet } 275\end{array}$ & $\begin{array}{l}\text { t.d.s. } \\
\text { t.d.s. } \\
\text { t.d.s. }\end{array}$ \\
\hline $\begin{array}{l}40 \\
69\end{array}$ & $\begin{array}{l}\mathrm{M} \\
\mathrm{F}\end{array}$ & $\begin{array}{l}1 \\
6\end{array}$ & I & $\begin{array}{l}\text { Sinemet Plus } 50 \mathrm{mg} \\
\text { Bromocryptine } 2 \cdot 5 \mathrm{mg} \\
\text { Benzhexol } 5 \mathrm{mg} \\
\text { Sinemet } 275\end{array}$ & $\begin{array}{l}\text { t.d.s. } \\
\text { t.d.s. } \\
\text { t.d.s. } \\
\text { t.d.s. }\end{array}$ \\
\hline $\begin{array}{l}58 \\
52\end{array}$ & $\begin{array}{l}\mathbf{F} \\
\mathbf{F}\end{array}$ & $\begin{array}{r}1 \\
12\end{array}$ & $\begin{array}{l}\text { II } \\
\text { IV }\end{array}$ & $\begin{array}{l}\text { Amantidine } 100 \mathrm{mg} \\
\text { Bromocryptine } 10 \mathrm{mg} \\
\text { Sinemet } 110\end{array}$ & $\begin{array}{l}\text { b.d. } \\
\text { g.d.s. } \\
5 \text { times a day }\end{array}$ \\
\hline
\end{tabular}

Elema Schonander EEG machine, with time marks applied to the paper.

Analysis of the record for sleep stage was performed by two of the investigators, using standard methods. ${ }^{14}$ Time to go to sleep, time to onset of rapid eye movement (REM) sleep, number of wakes during the night, and duration of stages W, I, II, III/IV, and REM were measured, as was total non REM sleep time, and total sleep time. Respiration during sleep was analysed to provide the respiratory rate when awake, taken from periods of stage $W$ before sleep, and during the night, respiratory rate during stage II sleep, and respiratory rate during REM sleep, the number, timing, and duration of apnoeas, and the haemoglobin oxygen saturation. The haemoglobin oxygen saturation for each minute was taken from the trace, and the record analysed for the whole night, to give results for the oxygen saturation in each sleep stage, and the time spent at each saturation percentage throughout the night. Parameters for sleep and respiration for the patients with idiopathic Parkinson's disease were compared with those from age and sex matched controls using Students paired $t$ test.

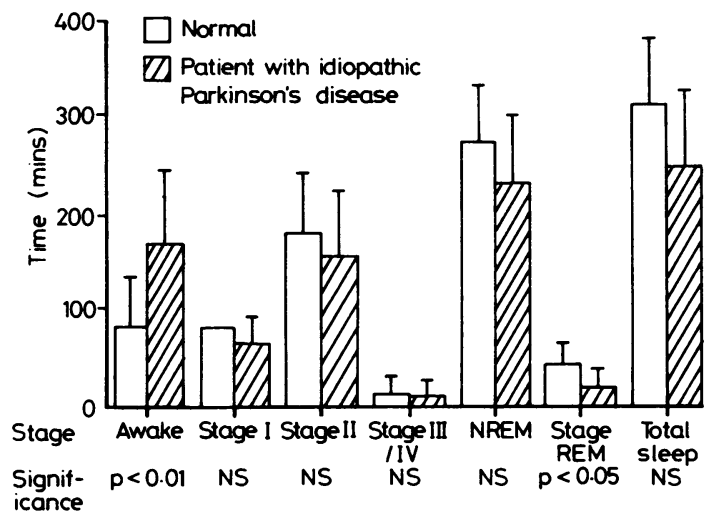

Fig 1 Steep stages in Parkinsonian patients and normal controls.

\section{Results}

IDIOPATHIC PARKINSON'S DISEASE PATIENTS

AND NORMAL CONTROLS

The 12 patients with idiopathic Parkinson's disease were compared with an equal number of age and sex matched normal controls. Details of age, sex, duration of disease, severity of disease, and medication for the patients is given in the table.

\section{Sleep}

Analysis of sleep revealed that the mean time taken for Parkinsonian patients to go to sleep was longer than that for the normals, but that this was not statistically significant (mean \pm standard deviation. Normals $16 \pm 10$ min, patients with idiopathic Parkinsonism $22.5 \pm 17 \mathrm{~min}$ ). During the night there were more frequent wakes in the patients with idiopathic Parkinson's disease (normals $6 \cdot 1 \pm 2 \cdot 0$; patients $8 \cdot 9$ $\pm 3 \cdot 1: p<0.05)$, and more time was spent awake in this group (normals $81 \pm 50 \mathrm{~min}$.; patients $169 \pm 77$ min: $p<0.01)$. This was associated with a significantly shorter duration of REM sleep in the Parkinsonian patients (normals $43 \pm 19 \mathrm{~min}$; patients $19.5 \pm 23$ min: $p<0.05$ ), six of whom showed evidence of REM sleep for less than 1 minute. There was no difference in the time spent in any of the stages of non REM sleep between the two groups. Total sleep time was shorter in the patient group than in the normal group, owing to a reduction in the duration of REM sleep in the patient group, but this did not reach statistical significance (fig 1). REM latency was similar in the two groups (normals $157 \pm 93 \mathrm{~min}$; patients $148 \pm 50 \mathrm{~min}$ ). On going to sleep the submental EMG decreased in both groups, and decreased further in both groups equally on going into REM sleep. 


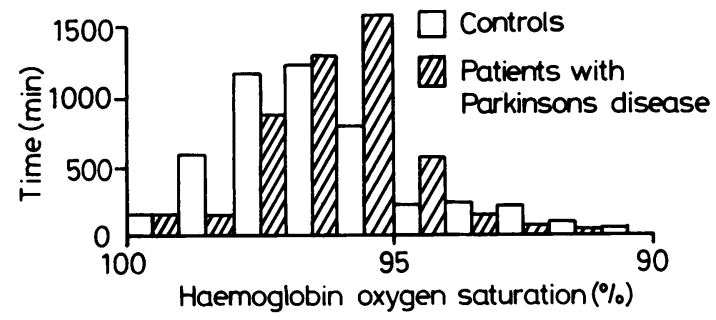

Fig 2 Haemoglobin oxygen saturation during the night.

\section{Haemoglobin oxygen saturation}

Haemoglobin oxygen saturation fell in all subjects during sleep, to the same extent in both groups (fig 2). Haemoglobin oxygen saturation was similar when awake (normals $96 \cdot 5 \pm 1 \cdot 3 \%$; patients $96.3 \pm$ $1.1 \%$ ), in stage II sleep (normals $95.8 \pm 1.8 \%$; patients $95.4 \pm 0.9 \%$ ), and in REM sleep (normals $95 \cdot 3 \pm 1 \cdot 9 \%$; patients $95 \cdot 5 \pm 0 \cdot 9 \%$ ). Minimum saturation was similar in the two groups (normals $91 \cdot 3 \pm$ $4.8 \%$; patients $95.5 \pm 2.0 \%$ ), and a similar proportion of time was spent with a haemoglobin oxygen saturation of $<95 \%$, (normals $16.5 \%$ of the night; patients $17 \%$ of the night), with very little time spent with a saturation of $<90 \%$ (normals 3 min; patients $1 \mathrm{~min}$ ).

\section{Respiratory rate and rhythm}

Respiratory rate was significantly faster in the patient group when awake, than in the normal controls (normals $13.9 \pm 1.1$ breaths/min; patients 17.9 $\pm 1.6: p<0.006$ ), but on going to sleep the respiratory rate decreased in the patient group so that in stage II sleep the respiratory rate was no longer significantly faster than the normal group. (normals $14.0 \pm 0.57$ breaths $/ \mathrm{min}$; patients $15.0 \pm$ 0.69: NS). During REM sleep the mean respiratory

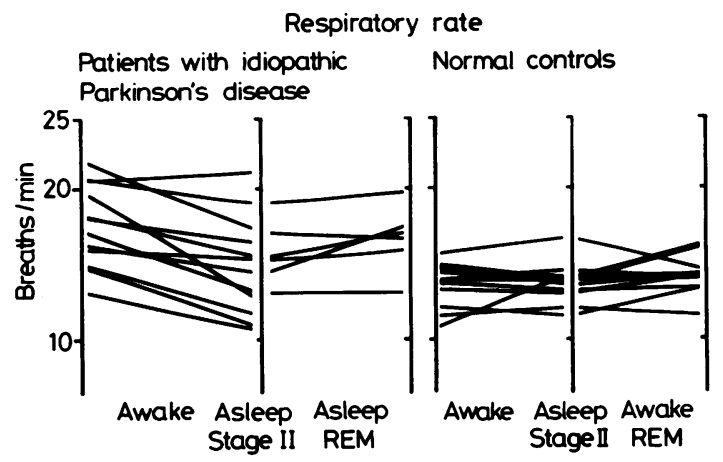

Fig 3 Respiratory rate awake and asleep. rate was greater in the patient group, with no significant change in the normal group (normals $14.6 \pm 1.6 / \mathrm{min}$; patients $17.0 \pm 1.4 / \mathrm{min}: \mathrm{p}<0.05)$ (see fig 3).

In only one subject was there any evidence of any significant number of apnoeic episodes. This was a 68-year-old normal control subject, who gave no history of snoring or disturbance of sleep. During the night he had 30 central apnoeas, and 10 obstructive apnoeic episodes, all occurring in Stage I NREM, or in REM sleep. None of the apnoeas were longer than 25 seconds, mean apnoea length was 20 seconds; there were no cardiac dysrhythmias, and although haemoglobin oxygen saturation fell during each apnoea, only 1 minute was spent during the whole night with a saturation of $<90 \%$. In five other normal subjects there were central apnoeas $(1,1,2$, 2,1 , apnoeas each), and in five of the patient group $(1,1,2,3,4$, apnoeas each), but none of these apnoeas lasted longer than $20 \mathrm{~s}$, and all apnoeas occurred during stage I NREM, or in REM sleep.

\section{PATIENTS WITH AUTONOMIC DYSFUNCTION}

Two patients with autonomic disturbance and Parkinsonian features were studied.

Patient 1 This 57-year-old lady had a 5 year history of Parkinsonism, severe postural hypotension, snoring and constipation. She showed severe lability of blood pressure, and had evidence of autonomic failure, with no change in pulse rate during a Valsalva manoeuvre. It was felt that this patient had orthostatic hypotension and idiopathic Parkinson's disease. There was no stridor when awake, and vocal cord movement was normal. The sleep study revealed a low $(85 \%)$ haemoglobin oxygen saturation when awake, which fell further on going to sleep (mean asleep, $82 \%$, minimum $80 \%$ ). The respiratory rhythm whilst asleep was irregular both in rate and volume, and respiration was noisy. There were occasional episodes of obstructive apnoea, in which there was no airflow despite continuing respiratory movement, and paradoxical movement of the chest inwards during attempted inspiration. There was little sleep, but frequent wakings after episodes of apnoea.

Patient 2 This 43-year-old man had first presented with urinary retention three years previously and been found to have a neuropathic bladder. Subsequently he developed a right extensor plantar response, pyramidal weakness of the right arm, minimal cerebellar signs, and mild extrapyramidal signs. Initially there was no postural hypotension, but this developed later, with an absent heart rate response to the Valsalva manoeuvre. This patient had many features of the Shy-Drager syndrome. Sleep study revealed grossly disturbed sleep, with frequent obs- 
tructive apnoeas leading to waking. The haemoglobin oxygen saturation was normal when awake, but fell on going to sleep, falling further during apnoeic episodes. During sleep the respiratory rate and rhythm were irregular. When awake there was evidence of upper airway obstruction and stridor, and indirect laryngoscopy revealed paralysis of abduction of the vocal cords.

\section{Discussion}

Sleep studies in patients with Parkinson's disease have shown a wide variety of abnormalities. An increase in sleep latency, frequency of waking during the night, and increased time spent awake, have all been described. ${ }^{25} 15$ The authors have reported reduced stage III/IV sleep, and a reduction in the duration of REM sleep. Other workers have reported normal stage IIV/IV sleep, ${ }^{16}$ or even completely normal sleep. ${ }^{17}$ These discrepancies have been explained in terms of there being two groups of patients with Parkinson's syndrome, one group with reduced REM sleep, and increased submental muscle activity during REM sleep, and the other with normal REM sleep, and repetitive blinking at the beginning of the night. ${ }^{18}$

Few of these studies have attempted, however, to differentiate patients according to aetiology, age, or severity of disease. ${ }^{3}$ Friedman $^{15}$ has shown for patients with Parkinson's disease that impairment of sleep may be directly related to the severity of disease. In addition, some of the abnormalities described in association with Parkinson's disease are present in a normal ageing population ${ }^{19}$ which makes the assessment of more elderly patients difficult.

We have studied a relatively young group of patients with idiopathic Parkinson's disease, and compared them with age and sex matched controls. Our results show frequent and prolonged waking in the Parkinsonian patients. There was a reduction in the duration of REM sleep, but no abnormalities of NREM sleep. These results are similar to those of Friedman, ${ }^{15}$ who found reduced stage III/IV sleep only in patients with severe disease (Hoehn and Yahr grade IV/V, and only one of our patients was in this group). We did not find either increased submental activity, or repetitive blinking in any of our patients, so it was not possible to analyse our data as did Mouret. ${ }^{18}$ In our patients there was no correlation between the severity of disease and limitation of REM sleep.

Several reports of an improvement with dopaminergic therapy, with prolongation of REM sleep duration, have suggested that dopamine deficiency is important in causing the sleep abnor- malities seen in these patients. ${ }^{2562021}$ All of our patients were receiving either Sinemet, Madopar, levodopa, amantidine, or bromocryptine, which increase dopamine activity centrally. It is possible that the abnormalities of sleep seen in our patients would have been more marked had they not been receiving such therapy, and this may explain why our results show less abnormality of sleep than some of the earlier studies. It is unlikely that the drug therapy itself caused the abnormalities seen, as previous studies have demonstrated similar abnormalities prior to therapy, with improvement on therapy.

In contrast to the patients with idiopathic Parkinson's disease, who showed only mild abnormalities of sleep, the two patients with Parkinsonism and autonomic dysfunction showed grossly disturbed sleep. In neither patient was there much organised sleep; apnoeas and obstructive episodes caused frequent arousals. McNicholas et al ${ }^{7}$ and Guilleminault ${ }^{22}$ have reported similar findings in patients with the Shy-Drager syndrome, although Parkinsonism was not a major feature in all their patients. Most of the abnormalities of sleep appear to be related to waking in response to arousal after central or obstructive apnoeas, which are rare in other Parkinsonian patients. It is probable that these abnormalities are more related to the autonomic failure in these patients, and are not related to the Parkinsonism.

McNicholas $\mathrm{et} \mathrm{al}^{7}$ have reported on respiration during sleep in three patients with idiopathic Parkinson's disease. They showed no evidence of sleep apnoea or desaturation during sleep, and noted a regular respiratory rhythm awake and asleep; they suggested that automatic control of respiration was normal in their patients with this condition. Our patients showed similar results, with no evidence of hypoventilation or significant sleep apnoeas. All case reports of hypoventilation in Parkinsonian patients have appeared in patients with postencephalitic Parkinsonism, or familial Parkinsonism. ${ }^{9-11} 1323$ In Parkinsonism following encephalitis lethargica there is evidence of more widespread brainstem damage than in idiopathic Parkinson's disease. ${ }^{24}$ Even after encephalitis lethargica only a small proportion of patients showed respiratory complications. ${ }^{25}$ Perhaps only with the widespread brainstem damage present in a few cases of encephalitis lethargica is there failure of automatic control of respiration, which may then lead to the hypoventilation and respiratory dysrhythmias which are characteristic of such failure of respiratory control.22 26

We observed a tachypnoea in our patients with idiopathic Parkinson's disease, which decreased on 
going to sleep. This tachypnoea might be related to central factors, either to the disease itself, or the effect of drugs, to the presence of respiratory disease, or to chest wall rigidity and stiffness as a result of the disease. Tachypnoea was a frequent finding during the encephalitic epidemic of the $1920 \mathrm{~s},{ }^{8}$ and has been reported since in patients with Parkinson's syndrome prior to the introduction of levodopa therapy. ${ }^{27-29}$ Tachypnoea, breathlessness, and respiratory dysrhythmias have been reported following levodopa therapy. ${ }^{30-34}$ Similar irregularity of respiration in patients with tardive dyskinesia, in whom excess dopamine activity has been implicated, have been reported..$^{35}$ All these observations suggest that both dopamine deficiency and dopamine excess may lead to tachypnoea and affect the respiratory rate and rhythm. In our patients there were no respiratory dysrhythmias or very fast tachypnoea characteristic of dopamine overactivity, but a slightly faster rate than normals, similar to that reported by $\mathrm{Kim}^{29}$ It is possible that this abnormality could be caused by dopamine underactivity from the disease, as despite therapy, the patients still had signs of Parkinsonism. Since we did not study the effect of alteration of drug dosage, it is not possible to say that the abnormality was not related to drug therapy.

An alternative explanation for our results would be that the patients had evidence of respiratory disease, but his was denied by our patients, and all patients had a normal awake haemoglobin oxygen saturation, which suggests that there was no respiratory disease sufficient to cause hypoxia. A further possible explanation for our results might be that the tachypnoea was caused by increased stiffness of the chest wall. Awake patients with Parkinson's syndrome show increased intercostal muscle activity throughout the respiratory cycle ${ }^{36}$ and this leads to increased stiffness of the chest wall. This might be expected to lead to increases in respiratory rate in compensation for the increased work of breathing. ${ }^{37}$

On going to sleep patients with Parkinson's disease lose their rigidity and tremor, and in our patients this was observed. Similarly on going to sleep the respiratory rate fell in the Parkinsonian patients but not in the normal controls. This may be explained in terms of alterations in the central control of breathing, or may be due to relaxation of the chest wall muscles, resulting in reduced work for breathing, hence leading to a reduction in respiratory rate. ${ }^{37}$ Either of these explanations fits our results. During REM sleep there is characteristically even more hypotonia than in non REM sleep, but respiration is less automatic, and depends more upon voluntary control. In our normal subjects there was a small increase in the respiratory rate; in the Parkinsonian patients there was no evidence of a further fall in respiratory rate, as might be expected if peripheral chest wall muscle tone was the sole determinant of rate. The respiratory rate increased slightly in those patients who had enough REM sleep for analysis, suggesting that central factors were more important in determination of the respiratory rate than the chest wall tone.

These minor abnormalities of respiratory rate seen in the patients with idiopathic Parkinson's disease are in complete contrast to the changes seen in patients with evidence of autonomic dysfunction. Both of these patients showed frequent apnoeic episodes when asleep, with falls in haemoglobin oxygen saturation, and a disorganised respiratory rhythm both awake and sleeping. It has been suggested that the disordered respiratory pattern seen in these patients is associated with a defect in the automatic respiratory rhythm generator in the brain stem. ${ }^{7}$ In addition, the obstructive episodes seen in our patients, and in those cases previously reported, ${ }^{72}$ are due to a failure of abduction of the vocal cords, causing obstruction of the larynx during inspiration. ${ }^{38}$ This vocal cord palsy was also present in one of our two patients when awake. As none of these abnormalities was seen in any of our patients with idiopathic Parkinson's disease, it is probable that their occurrence is due to the disease which results in the central autonomic dysfunction in these patients and not the Parkinson's disease itself.

Patients with idiopathic Parkinson's disease show abnormal sleep with frequent waking and reduced REM sleep. They also show a tachypnoea when awake, that disappears when they go to sleep, and have a normal haemoglobin oxygen saturation both awake and asleep, with no evidence of sleep apnoea. Patients with autonomic dysfunction and Parkinsonism, in contrast, show grossly disturbed respiration, with hypoventilation and disorganised respiratory rhythm, and wake frequently, showing very little normal sleep. Both Parkinson's disease, and the drugs used in its treatment appear to affect both respiration and sleep. These respiratory effects may be due to either direct central effects on the respiratory rhythm generation, to effects on the respiratory rate due to changing chest wall tone, or to a combination of the two.

\section{References}

' Kales A, Anael RD, Markham CH, Dcharf MB, Tijauw Ling Tan. Sleep in patients with Parkinson's disease and normal subjects prior to and following levodopa administration. Clin Pharmacol Therap 1971;4:397406.

${ }^{2}$ Kendel K, Beck U, Wita C, Hohneck E, Zimmerman H. 
Der Einfluss von L dopa auf den Nachtschlaf bei patienten mit Parkinson-Syndrom. Arch Psychiatr Nervenkr 1972;216:82-100.

${ }^{3}$ Traczynska Kubin D, Atzef E, Petre Quadens O. Le Sommeil dans la maladie de Parkinson. Acta Neurol Belg 1969;69:727-33.

${ }^{4}$ Jouvet M. The role of monoamines and acetylcholine containing neurones in the regulation of the sleep waking cycle. Rev Physiol Biochem Pharmacol 1972;64:166-307.

${ }^{5}$ Bergonzi P, Chiurulla C, Tempesta E. Clinical pharmacology as an approach to the study of biochemical sleep mechanisms. The action of $\mathrm{L}$ dopa. Confin Neurol 1974;36:5-22.

- Rabey J, Vardi J, Glaubman H, Streifler M. EEG sleep study in Parkinsonian patients under bromocryptine treatment. Eur Neurol 1978;17:345-50.

${ }^{7}$ McNicholas WT, Rutherford R, Grossman R, Moldofsky $\mathrm{H}$, Zamel $\mathrm{N}$, Phillipson EA. Abnormal respiratory pattern generation during sleep in patients with autonomic dysfunction. Am Rev Respir Dis 1983;128:429-33.

${ }^{8}$ Turner WA, Critchley M. Respiratory disorders in Epidemic Encephalitis. Brain 1925;48:72-104.

${ }^{9} \mathrm{Da}$ Costa JL. Chronic hypoventilation due to diminished sensitivity of the respiratory centre associated with Parkinsonism. Med J Aust 1972;1:373-6.

${ }^{10}$ Garlind T, Linderholm H. Hypoventilation syndrome in a case of chronic Epidemic Encephalitis. Acta Med Scand 1958; 162:333-49.

"Streider DJ, Baker WG, Baringer JR, Kazemi H. Chronic Hypoventilation of central origin. A case with encephalitis lethargica and Parkinson's syndrome. Am Rev Respir Dis 1966;96:501-97.

12 Perry TL, Bratty PJA, Harsen S. Hereditary mental depression and Parkinsonism with taurine deficiency. Arch Neurol 1975;32:108-13.

${ }^{13}$ Purdy A, Hahn A, Barnett JM, et al. Familial fatal Parkinsonism with alveolar hypoventilation and mental depression. Ann Neurol 1979;6:523-31.

${ }^{14}$ Rechtschauffen A, Kales A. A Manual of standardised Terminology, Technique, and scoring for sleep stages in human subjects. Brain Information Service/Brain Research Institution, University of California, 1968.

15 Friedman A. Sleep pattern in Parkinson's disease. Acta Med Pol 1980;21:193-9.

${ }^{16}$ Wein A, Golubev V, Yakhno N. Polygraphic analysis of sleep and wakefulness in patients with Parkinson's syndrome. Waking and Sleeping 1979;3:33-40.

${ }^{17}$ Greenberg R, Pearlman CA. L dopa, Parkinsonism, and sleep. Psychophysiology 1970; 7:314.

${ }^{18}$ Mouret J. Differences in sleep in patients with Parkinson's disease. Electroencephalogr Clin Neurophysiol 1975; 38:653-7.

19 Dement WC, Miles LE, Carskadon MA. "White Paper" on sleep and ageing. J Am Geriatr Soc 1982;30:2550.

${ }^{20}$ Bricolo A, Turella G, Mazza CA, Buffati P, Grosslercher JC. Modificazioni del sonno notturno in Parkinsoniani con L dopa. Sist Nerv 1.970;22:181-90.
${ }^{21}$ Schneider E, Maxion H, Ziegler B, Jacobi P. Das Schlarferhalten von Parkinsonkranken und seine Beinflussung durch 1 dopa. J Neurol 1974;207:95108.

${ }^{22}$ Guilleminault C, Tilkian A, Lehrman K, Forno L, Dement WC. Sleep apnoea syndrome, states of sleep, and autonomic dysfunction. J Neurol Neurosurg Psychiatry 1977;40:718-25.

${ }^{23}$ Phillipson EA. Regulation of breathing during sleep. Am Rev Respir Dis 1977;115(Suppl):217-24.

${ }^{24}$ Greenfield JG, Bosanquet FS. The brainstem lesions in Parkinsonism. J Neurol Neurosurg Psychiatry 1953; 16:213-26.

${ }^{25}$ Ziegler LH. Follow up studies in persons who have had epidemic encephalitis. JAMA 1928;91:138-41.

${ }^{26}$ Remmers JE. Effects of sleep on control of breathing. In: Widdicombe JJ, ed. International Review of Physiology. Respiratory Physiology III, vol 23. Baltimore: University Park Press, 1981:113-34.

${ }^{27}$ Grewel F. Dysarthria in post encephalitic Parkinsonism. Acta Psychiatrica Neurol Scand 1957;32:440-9.

${ }^{28} \mathrm{Neu}$ HC, Connolly JJ, Schwertley FW, Ladwig HA, Brody AW. Obstructive respiratory dysfunction in Parkinsonian patients. Am Rev Respir Dis 1967;95:33-47.

${ }^{29} \mathrm{Kim} \mathrm{R}$. The chronic residual respiratory disorder in post encephalitic Parkinsonism. J Neurol Neurosurg Psychiatry 1968;31:393-8.

${ }^{30}$ Granerus AK, Jagenburg R, Nilsson NJ, Svanborg A. Respiratory disturbance during levodopa treatment of Parkinson's syndrome. Acta Med Scand 1974; 195: 39-43.

${ }^{31}$ Sacks OW, Kohl M, Schwartz W, Meseloff C. Side effects of 1 dopa in postencephalitic Parkinsonism. Lancet 1970:1006.

${ }^{32}$ Barbeau A. L dopa in Parkinson's disease, a critical review of nine years experience. Can Med Assoc J 1969;101:59-68.

${ }^{33}$ Calne DB, Stern GM, Lawrence DR, Sharkey J, Armitage $P$. L dopa in postencephalitic Parkinsonism. Lancet 1969:744-7.

${ }^{34}$ Newsom Davis J. Pattern of breathing in disease, general considerations. Bull Eur Physiopathol Respir 1975;11:113-115P.

${ }^{35}$ Wiener WJ, Goetz CG, Nausieda PA, Klawans HL. Respiratory dyskinesias, extrapyramidal dysfunction, and dyspnoea. Am J Int Med 1978;88:327-31.

${ }^{36}$ Delhex L, Petit JM. Quelques modalités de l'activité des muscles respiratoire chez le Parkinsonien (Controle Electromyographique). Rev Franc Etudes Clin et Biol $1961 ; 6: 580-4$

${ }^{37}$ Mead J. Control of respiratory frequency. J Appl Physiol 1960;15:325-36.

${ }^{38}$ Williams A, Hanson D, Calne DB. Vocal cord paralysis in the Shy Drager Syndrome. J Neurol Neurosurg Psychiatry 1979;42:151-3.

${ }^{39}$ Hoehn MM, Yahr MD. Parkinsonism: onset, progression, and mortality. Neurology (Minneap) 1967:17:527-42. 